\title{
Efeito do manejo de fornecimento de colostro na imunidade passiva, cortisol e metabólitos plasmáticos de bezerros Holandeses
}

\author{
[Effects of colostrum supply manner on passive immunity and levels of cortisol \\ and plasmatic metabolites of Holstein calves] \\ F.A. Paiva ${ }^{1}$, J.A. Negrão ${ }^{2}$, A.R. Bueno ${ }^{3}$, A. Saran-Netto ${ }^{1}$, C.G. Lima $^{2}$ \\ ${ }^{1}$ Aluno de pós-graduação - FZEA - USP, Pirassununga,SP \\ ${ }^{2}$ Faculdade de Zootecnia e Engenharia de Alimentos - USP \\ Caixa Postal 23 \\ 13630-000 - Pirassununga, SP \\ ${ }^{3}$ UniABC - São Paulo, SP
}

\begin{abstract}
RESUMO
Avaliou-se a influência do manejo de fornecimento de colostro nas concentrações de imunoglobulina $G$, glicose, proteína total, triglicerídeos, lactato e cortisol de 18 bezerros da raça Holandesa. Os animais foram distribuídos em três tratamentos: $\mathrm{T} 1$ - os bezerros foram separados das vacas $6 \mathrm{~h}$ após o nascimento, mamando em suas mães, por 30 minutos, duas vezes ao dia, nos três primeiros dias; T2 - os bezerros foram separados $6 \mathrm{~h}$ após o nascimento e nos três primeiros dias receberam o colostro em mamadeiras, duas vezes ao dia, quando receberam 21/refeição; T3 - permaneceram o tempo todo com as vacas durante os três primeiros dias de vida. Foram colhidas amostras de sangue nos tempos de $0 ; 12 ; 24 ; 48 ; 72$ e $96 \mathrm{~h}$ após o nascimento. Os valores de $\mathrm{IgG}$ do T3 foram mais altos que os encontrados no $\mathrm{T} 1$, às $24 \mathrm{~h}(\mathrm{P}<0,10)$. No T3, os níveis de glicose foram mais elevados que os verificados nos demais tratamentos $(\mathrm{P}<0,10)$. Os níveis de proteína total no T2 foram maiores que no T1 $(\mathrm{P}<0,10)$. As concentrações de cortisol e lactato foram maiores ao nascimento nos três tratamentos $(\mathrm{P}<0,10)$. Conclui-se que o T2 seria o manejo mais indicado por sua praticidade.
\end{abstract}

Palavras-chave: bezerro, amamentação, desmame, imunoglobulina G, estresse

\begin{abstract}
The influence of colostrum supply on immunoglobulin $G$, glucose, total protein, triglycerides, lactate and cortisol concentrations of 18 Holstein calves, was evaluated. Calves were allotted to three treatments, T1 - calves were separated from cows 6h after birth, nursing 30 minutes a day in their mothers, twice a day in the first three days; $T 2$ - calves were separated 6 h after birth, and in the first three days they received colostrum through nipple bottles twice a day, 2l/meal; and 73 - calves remained all the time with cows during the first three days. Blood samples were taken at times 0; 12; 24; 48; 72 and $96 \mathrm{~h}$ after birth. IgG levels were higher in T3 than in T1 at $24 \mathrm{~h}(P<0.10)$. Glucose levels were higher in T3 than in the other treatments $(P<0.10)$. Total protein levels in $T 2$ were higher than in $T 1(P<0.10)$. Cortisol and lactate concentrations at birth were higher in all treatments $(P<0.10)$. Howewer, 22 would be more indicated for its feasibility.
\end{abstract}

Keywords: calf, suckling, weaning, immunoglobulin G, stress

Recebido em 6 de abril de 2005

Aceito em 28 de julho de 2006

E-mail: fe_paiva@yahoo.com 


\section{INTRODUÇ̃̃O}

Diversos fatores podem interferir na aquisição de imunidade adequada pelo bezerro, dentre os quais está o manejo de fornecimento de colostro, que realizado de forma inadequada pode comprometer todo o desenvolvimento do animal (Ramin et al., 1996).

Além da transferência de imunidade passiva, o colostro também tem função nutricional, pois logo após o parto as reservas energéticas do recém-nascido são limitadas (Campana e Baumrucker, 1995). Embora haja grande metabolização de glicogênio e de tecido adiposo, os mesmos se exaurem rapidamente (Girard, 1986). Assim, a manutenção da homeostasia torna-se dependente da quantidade e da qualidade nutricional do colostro ingerido (Kuhne et al., 2000).

Embora não se conheçam bem as causas, bezerros amamentados pelas mães no período de colostro apresentaram níveis mais elevados de imunoglobulinas séricas (Fallon et al., 1989), menor incidência de diarréias (Nocek et al., 1984) e menor taxa de mortalidade (Lovell e Hill, 1940) que bezerros que receberam colostro em baldes ou mamadeiras. Entretanto, Zanetti et al. (1982) observaram que uma parcela significativa de bezerros, tanto aqueles deixados com a mãe como aqueles que receberam colostro no balde, não mamaram e/ou não absorveram quantidade adequada de imunoglobulinas. As prováveis razões dessa deficiência seriam: ingestão de quantidade inadequada e/ou baixa concentração de imunoglobulinas no colostro, administração tardia de colostro ou perda precoce da capacidade de absorção.

Assim, o objetivo do presente trabalho foi avaliar a influência do manejo de fornecimento de colostro na aquisição de imunidade passiva e nas concentrações de glicose, proteína total, triglicerídeos, lactato e cortisol de bezerros holandeses.

\section{MATERIAL E MÉTODOS}

Foram utilizados 18 bezerros da raça Holandesa, machos ou fêmeas, distribuídos em três tratamentos $(\mathrm{T})$. T1 - os bezerros foram separados das vacas seis horas após o nascimento, mas durante os três primeiros dias de vida permaneceram com elas durante 30 minutos, duas vezes ao dia, para mamarem o colostro; após a amamentação, as vacas seguiram para a ordenha mecânica. T2 - os bezerros foram separados das vacas seis horas após o nascimento e durante os três primeiros dias de vida receberam colostro através de mamadeira, duas vezes ao dia, dois litros por refeição. O colostro oferecido ao bezerro era de sua mãe, obtido após a ordenha. T3 - os bezerros permaneceram com as vacas durante os três primeiros dias de vida, em piquete isolado dos demais animais. Duas vezes ao dia, as vacas eram ordenhadas sem o bezerro.

Em cada tratamento, havia três bezerros nascidos de vacas primíparas e três nascidos de vacas multíparas. Os bezerros foram pesados logo após o nascimento e ao final do experimento.

O sangue foi colhido na veia jugular dos animais (tubos tipo vacutainer heparinizados), nos tempos $0 ; 12 ; 24 ; 48 ; 72$ e 96 horas após o nascimento. Os bezerros foram separados de suas mães às $72 \mathrm{~h}$; na última colheita, às $96 \mathrm{~h}$, todos os bezerros já não tinham mais contato com suas mães. O sangue colhido foi conservado no gelo e depois centrifugado por 15 minutos, em $1500 \mathrm{~g}$, a $4^{\circ} \mathrm{C}$, para a obtenção do plasma que foi conservado a $-30^{\circ} \mathrm{C}$ até o momento de ser analisado.

$\mathrm{Na}$ determinação das concentrações de glicose, proteína total, triglicerídeos lactato e cortisol, foram utilizados kits comerciais ${ }^{1,2}$. Para a determinação plasmática da imunoglobulina $\mathrm{G}$, foi utilizado o método de imunodifusão radial em placas de ágar (Mancini et al., 1965), adaptado por Pauletti (1999).

O delineamento experimental foi em blocos ao acaso, com seis repetições, em que os blocos foram criados em função da ordem de parto das vacas. Os dados de IgG, cortisol, glicose, proteína total, triglicerídeos e lactato envolveram medidas repetidas no tempo (colheitas ao nascimento e às 12 (exceto para o cortisol), 24, 48, 72 e 96 horas após o nascimento), foram analisados com o proc mixed do User's... (2000),

${ }^{1}$ Laborlab S/A - Guarulhos/São Paulo-Brasil

${ }^{2}$ Diagnostic Systems Laboratories - Webster/Texas - EUA 
assumindo um modelo com os efeitos de bloco, tratamento, colheita e interação tratamento $\mathrm{x}$ colheita. As diferenças entre as médias foram testadas pelo teste de $\mathrm{t}$-Student $(\mathrm{P}<0,10)$.

\section{RESULTADOS E DISCUSSÃO}

A Tab. 1 mostra as concentrações plasmáticas médias de imunoglobulina $\mathrm{G}$, glicose, proteína total, triglicerídeos, lactato e cortisol dos bezerros dos três tratamentos.

O peso dos bezerros não foi influenciado pelos tratamentos, sendo que a média dos pesos ao nascimento foi $36,25+0,57 \mathrm{~kg}$ e a média dos pesos ao final do período experimental foi de $37,84 \pm 0,55 \mathrm{~kg}$.

Tabela 1. Concentrações plasmáticas médias e respectivos erros-padrão de imunoglobulina $G$ (IgG), glicose, proteína total (PT), triglicerídeos (Trig), lactato e cortisol de bezerros submetidos a diferentes manejos na fase colostral

\begin{tabular}{|c|c|c|c|c|c|c|c|}
\hline Colheita & $\mathrm{T}$ & $\mathrm{IgG}(\mathrm{mg} / \mathrm{ml})$ & Cortisol (mg/dl) & Glicose (mg/dl) & PT (g/dl) & Trig (mg/dl) & Lactato $(\mathrm{mg} / \mathrm{dl})$ \\
\hline \multirow{3}{*}{ Nascimento } & 1 & $0,00 \pm 0,00$ & $100,04 \pm 0,87$ & $70,48 \pm 5,93$ & $3,99 \pm 0,54$ & $282,82 \pm 21,55 b$ & $64,64 \pm 12,25$ \\
\hline & 2 & $0,00 \pm 0,00$ & $93,25 \pm 0,96$ & $61,52 \pm 8,02$ & $4,42 \pm 0,57$ & $487,18 \pm 102,59^{a}$ & $63,67 \pm 14,17$ \\
\hline & 3 & $0,00 \pm 0,00$ & $107,33 \pm 0,83$ & $70,70 \pm 15,15$ & $4,37 \pm 0,29$ & $300,08+32,79 \mathrm{~b}$ & $51,91 \pm 12,44$ \\
\hline \multicolumn{2}{|c|}{ Média da colheita } & $0,00 \pm 0,00 B$ & $100,21 \pm 0,55 \mathrm{~A}$ & $67,57 \pm 5,39 \mathrm{C}$ & $4,26 \pm 0,28 \mathrm{~B}$ & $356,69 \pm 63,01 A$ & $60,07 \pm 7,51 \mathrm{~A}$ \\
\hline \multirow{3}{*}{$12 \mathrm{~h}$} & 1 & $22,30 \pm 2,26$ & - & $85,71 \pm 17,40 \mathrm{~b}$ & $4,11+0,52 b$ & $201,51 \pm 17,05$ & $42,56+8,65$ \\
\hline & 2 & $20,64 \pm 3+65$ & - & $76,99+9,54 b$ & $5,11 \pm 0,18^{\mathrm{a}}$ & $246,72 \pm 26,74$ & $47,18+10,58$ \\
\hline & 3 & $24,19 \pm 2,59$ & - & $105,70 \pm 6,89^{\mathrm{a}}$ & $5,43 \pm 0,51^{\mathrm{a}}$ & $258,32 \pm 32,63$ & $50,84 \pm 8,98$ \\
\hline \multicolumn{2}{|c|}{ Média da colheita } & $22,38+1.61 \mathrm{~A}$ & - & $89,47 \pm 7,19$ B & $4,88+0,27 \mathrm{~B}$ & $235,51+15,44 B$ & $46,86+5,19 \mathrm{~B}$ \\
\hline \multirow{3}{*}{$24 \mathrm{~h}$} & 1 & $22,44+2,54 \mathrm{~b}$ & $68,33 \pm 1,48$ & $96,95+13,22 b$ & $4,33+0,75 b$ & $205,47 \pm 18,21 \mathrm{~b}$ & $50,89 \pm 8,55$ \\
\hline & 2 & $26,85 \pm 2,26 \mathrm{~b}$ & $57,44 \pm 0,96$ & $96,90 \pm 7,11 \mathrm{~b}$ & $6,69 \pm 0,53^{\mathrm{a}}$ & $250,78 \pm 29,27^{\mathrm{a}}$ & $42,72 \pm 8,51$ \\
\hline & 3 & $29,60+2,02^{\mathrm{a}}$ & $43,49 \pm 0,74$ & $121,2 \overline{6}+8,93 \mathrm{a}$ & $5,69 \pm 0,93 \mathrm{ab}$ & $188,59 \pm 19,37 \mathrm{~b}$ & $40,51 \pm 6,05$ \\
\hline \multicolumn{2}{|c|}{ Média da colheita } & $26,30+1,43 \mathrm{~A}$ & $56,42+0,65 \mathrm{~B}$ & $105,04+6,14 \mathrm{~A}$ & $5,57+0,47 \mathrm{~A}$ & $214,94+13,92$ B & $44,71+4,36 \mathrm{~B}$ \\
\hline \multirow{3}{*}{$48 \mathrm{~h}$} & 1 & $32,88 \pm 3,95$ & $70,96 \pm 1,91$ & $104,81 \pm 7,65 b$ & $4,39 \pm 0,47 \mathrm{~b}$ & $211,03 \pm 16,43$ & $41,25 \pm 7,78$ \\
\hline & 2 & $35,36 \pm 2,61$ & $69,79 \pm 1,58$ & $103,48+10,29 b$ & $6,18 \pm 0,40^{\mathrm{a}}$ & $243,20 \pm 25,09$ & $31,55 \pm 4,45$ \\
\hline & 3 & $34,34 \pm 1,10$ & $62,49 \pm 0,67$ & $137,03+5,20^{\mathrm{a}}$ & $5,65 \pm 0,78 \mathrm{ab}$ & $246,89 \pm 12,31$ & $31,70 \pm 5,89$ \\
\hline \multicolumn{2}{|c|}{ Média da colheita } & $34,20+1,54 \mathrm{~A}$ & $67,75+0,86 \mathrm{~B}$ & $115,11+5,74 \mathrm{~A}$ & $5,41+0,36 \mathrm{~A}$ & $233,71+10,88 B$ & $34,83+3,53 \mathrm{C}$ \\
\hline \multirow{3}{*}{$72 \mathrm{~h}$} & 1 & $32,23 \pm 2,37 b$ & $62,87 \pm 1,66$ & $99,23 \pm 15,40 \mathrm{~b}$ & $4,93 \pm 0,87 \mathrm{~b}$ & $201,90 \pm 9,95$ & $42,03 \pm 6,53$ \\
\hline & 2 & $30,68 \pm 2,16 b$ & $55,77 \pm 1,41$ & $100,0 \overline{8}+4,66 \mathrm{~b}$ & $5,96 \pm 0,58^{\mathrm{a}}$ & $239,98 \pm 28,51$ & $30,63 \pm 2,53$ \\
\hline & 3 & $38,52+3,30 \mathrm{a}$ & $57,35 \pm 1,10$ & $148,25 \pm 10,62^{\mathrm{a}}$ & $5,47 \pm 0,96 \mathrm{ab}$ & $218,93 \pm 25,43$ & $30,45 \pm 8,83$ \\
\hline \multicolumn{2}{|c|}{ Média da colheita } & $33,81 \pm 1,66 \mathrm{~A}$ & $58,66 \pm 0,77$ B & $115,85+8,20 \mathrm{~A}$ & $5,45 \pm 0,46 \mathrm{~A}$ & $220,27 \pm 13,53 B$ & $34,37 \pm 3,76 \mathrm{C}$ \\
\hline \multirow{3}{*}{$96 \mathrm{~h}$} & 1 & $30,92+1,91$ & $76,49 \pm 1,47$ & $86,87 \pm 12,80 b$ & $5,53+0,77$ & $192,38 \pm 16,40$ & $44,57 \pm 5,20$ \\
\hline & 2 & $30,83 \pm 2,39$ & $63,16 \pm 1,96$ & $103,74 \pm 11,71 b$ & $5,79 \pm 0,72$ & $228,40 \pm 27,79$ & $41,28 \pm 6,57$ \\
\hline & 3 & $36,66 \pm 3,72$ & $72,70 \pm 1,75$ & $129,50 \pm 5,48^{\mathrm{a}}$ & $5,40 \pm 0,80$ & $198,19 \pm 35,44$ & $35,11 \pm 9,55$ \\
\hline Média da & 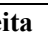 & $32,80+1,65 \mathrm{~A}$ & $70,78+0,95 B$ & $106,70+6,99 \mathrm{~A}$ & $5,57 \pm 0,42 \mathrm{~A}$ & $206,32+16,10 \mathrm{~B}$ & $40,32+4,09 \mathrm{~B}$ \\
\hline
\end{tabular}

Médias seguidas por letras diferentes na coluna diferem pelo teste $\mathrm{t}(\mathrm{P}<0,10)$. Letras maiúsculas indicam diferenças entre as colheitas; letras minúsculas indicam diferenças entre tratamentos em cada colheita.

T1=bezerros que mamaram nas vacas duas vezes ao dia, por 30 minutos, durante três dias; T2=bezerros que mamaram colostro na mamadeira; T3=bezerros que permaneceram com as vacas durante três dias.

Houve efeito significativo da interação tratamento versus tempo de colheita nos níveis plasmáticos de imunoglobulina $\mathrm{G}$ dos bezerros $(\mathrm{P}<0,10)$. Em todos os tratamentos, os valores plasmáticos de $\operatorname{IgG}$ encontrados logo após o parto foram iguais a zero, não diferindo entre si $(\mathrm{P}>0,10)$. Após a ingestão de colostro, os níveis de IgG aumentaram significativamente para todos os tratamentos $(\mathrm{P}<0,10)$, que não diferiram entre si às 12 horas $(\mathrm{P}>0,10)$.

Contudo, às 24 e 72 horas, os bezerros que permaneceram com suas mães apresentaram valores de $\mathrm{IgG}$ mais altos que os encontrados nos animais que apenas mamaram em suas mães $(\mathrm{P}<0,10)$. Os que receberam colostro através de mamadeiras (T2) apresentaram valores intermediários de $\mathrm{IgG}$ às 24 horas, não diferindo dos outros dois tratamentos $(\mathrm{P}>0,10)$. Entretanto, essas diferenças entre tratamentos não persistiram, pois não houve diferença entre eles às 48 e 96 horas $(\mathrm{P}>0,10)$.

Esse conjunto de resultados sugere que a administração artificial de colostro é adequada em fornecer imunidade passiva (T2), próxima 
àquela provida diretamente aos bezerros pelas suas mães (T3). Também demonstra que o fato de o bezerro mamar diretamente na vaca não garante melhor transferência de imunidade passiva, se outros fatores, como a quantidade de colostro ingerida, não forem levados em consideração (Besser et al., 1985), o que pode ter influenciado os níveis plasmáticos de IgG dos bezerros que mamaram em suas mães em períodos pré-determinados (T1).

Neste experimento, todos os valores de $\operatorname{IgG}$ encontrados às 24, 48, 72 e 96 horas de vida estavam acima da concentração plasmática mínima descrita na literatura como a ideal para garantir a imunidade adequada ao bezerro (10mg/ml (Wells, 1996)), sugerindo que todos os tratamentos testados foram eficazes na transmissão da imunidade passsiva.

Os níveis plasmáticos de cortisol foram influenciados apenas pelo tempo de colheita $(\mathrm{P}<0,10)$, quando os maiores valores foram encontrados logo após o nascimento, nos três tratamentos. Após o nascimento, a sobrevivência do recém-nascido depende de intensas mudanças nos padrões respiratório e circulatório. Esse processo adaptativo é dependente da ativação do eixo hipotálamo-hipófise-adrenal do bezerro, sendo mediado principalmente pelo cortisol, um potente estimulador do metabolismo (Wood, 1999).

Com a ingestão do colostro, os níveis de cortisol caíram e permaneceram relativamente estáveis para todos os grupos experimentais, possivelmente porque a partir desse momento a mobilização das reservas corporais do bezerro também foi menor. Por outro lado, os níveis plasmáticos de cortisol dos bezerros não estavam elevados após o desmame ( $\mathrm{P}>0,10)$, nem mesmo nos bezerros que permaneceram três dias com suas mães. Estes dados indicam que os três manejos adotados não causaram estresse fisiológico nos bezerros, diferente do que foi encontrado por Lidfords (1996).

Os níveis plasmáticos de glicose foram influenciados pela interação tratamento versus tempo de colheita $(\mathrm{P}<0,10)$. Os menores valores foram observados após o nascimento $(\mathrm{P}<0,10)$. Logo após a ingestão do colostro, os níveis de glicose aumentaram gradual e significativamente até às 48 horas $(\mathrm{P}<0,10)$, permanecendo estáveis até às 96 horas $(\mathrm{P}>0,10)$. Uma evolução semelhante dos níveis plasmáticos de glicose foi descrita, preliminarmente, por Kuhne et al. (2000).

Todavia, os bezerros que permaneceram com suas mães durante três dias (T3) apresentaram níveis de glicose mais altos que os dos demais tratamentos $(\mathrm{P}<0,10)$, reforçando a hipótese de que esses animais ingeriram maior quantidade de colostro. Segundo Kuhne et al. (2000), a concentração plasmática de glicose dos bezerros depende diretamente da quantidade ingerida e da concentração de lactose presente na secreção láctea.

Os níveis plasmáticos de proteína total também foram influenciados pela interação tratamento versus tempo de colheita $(\mathrm{P}<0,10)$. Os menores valores foram observados após o nascimento, aumentando na colheita das 24 horas $(\mathrm{P}<0,10)$ e permanecendo estáveis até às 96 horas $(\mathrm{P}>0,10)$. Esse tipo de evolução nos níveis de proteína total foi previamente descrito por Rauprich (2000).

Os bezerros que receberam colostro na mamadeira apresentaram níveis de proteína total mais elevados que os bezerros que mamaram duas vezes ao dia em suas mães até o desmame (72h) $(\mathrm{P}<0,10)$. Provavelmente, essa diferença ocorreu devido a esse último grupo ter ingerido menor volume de colostro durante o tempo que permaneceu com as vacas (30 minutos antes de cada ordenha).

Os níveis plasmáticos de triglicerídeos dos bezerros foram influenciados pela interação tratamento versus tempo de colheita $(\mathrm{P}<0,10)$. Às 12 horas após o nascimento, os animais que mamaram colostro em suas mães duas vezes ao dia apresentaram níveis de triglicerídeos mais baixos do que os demais bezerros $(\mathrm{P}<0,10)$. Às 24 horas, os bezerros que receberam colostro na mamadeira apresentaram níveis de triglicerídeos mais altos que os demais bezerros $(\mathrm{P}<0,10)$.

Contudo, não houve diferenças significativas entre os tratamentos nas demais colheitas experimentais $(\mathrm{P}>0,10)$. Como a concentração plasmática de triglicerídeos também é influenciada pela quantidade de colostro ingerida (Kuhne et al., 2000), as diferenças observadas no presente experimento sugerem que houve variação importante no consumo de colostro e no 
metabolismo dos bezerros experimentais nos primeiros dias de vida.

Os níveis de lactato dos bezerros foram influenciados apenas pelo tempo de colheita $(\mathrm{P}<0,10)$, sendo as maiores concentrações observadas ao nascimento. Essas altas concentrações de lactato são conseqüências da hipoxia e refletem a intensa metabolização das reservas energéticas do bezerro após 0 nascimento, causada, em parte, pelo aumento da atividade simpática devido ao estresse adaptativo do nascimento (Steinhardt et al. 1995).

Posteriormente, houve redução progressiva e significativa nos níveis plasmáticos de lactato entre as colheitas das 12 e 72 horas $(\mathrm{P}<0,10)$. Segundo alguns autores, a ingestão de colostro promoveria a elevação temporária da insulina circulante (Blum et al., 1997), estimulando progressivamente a formação do lactato (Donkin e Armentando, 1995). Aparentemente, essas mesmas alterações metabólicas causadas pela ingestão de colostro foram observadas no presente experimento.

\section{CONCLUSÃO}

Pode-se concluir que, embora os três tratamentos tenham propiciado transmissão de imunidade adequada aos bezerros, sem ocasionar estresse fisiológico, o fornecimento artificial de colostro seria o mais indicado por sua praticidade.

\section{REFERÊNCIAS BIBLIOGRÁFICAS}

BESSER, T.E.; GARMEDIA, A.E.; MCGUIRE, T.C. et al. Effects of colostral IgG1 and IgM concentrations on immunoglobulin absorption in calves. J. Dairy Sci., v.68, p.2033-2037, 1985.

BLUM, J.W.; HADORN, U.; SALLMANN, H.P. et al. Delaying colostrum intake by one day impairs the plasma lipid, essential fat acid, carotene, retinol and I-tocopherol status in neonatal calves. J. Nutr., v.127, p.2024-2029, 1997.

CAMPANA, W.M.; BAUMRUCKER, C.R. Hormones and growth factors in bovine milk. In: JENSEN, R.G. (Ed.). Handbook of milk composition. New York: Academic, 1995. p.476-494.

DONKIN, S.S.; ARMENTANDO, L.E. Insulin and glucagon regulation of gluconeogenesis in preruminanting and ruminanting bovine. J. Anim. Sci., v.73, p.546-551, 1995.
FALLOW, R.J.; HARET, F.J.; DEANE, M.G. Methods of artificially feeding colostrums to the new-born calf Ir. J. Agri. Res., v.28, p. 57-63, 1989.

GIRARD J. Gluconeogenesis in late fetal and early neonatal life. Biol. Neonate, v.50, p.237-258, 1986

KUHNE, S.; HAMMON, H.M.; BRUCKMAIER, R.M. et al. Growth performance, metabolic and endocrine traits, and intestinal absorptive capacity in neonatal calves fed either colostrum or milk replacer at low and high intensities. $J$. Anim. Sci., v.78, p.609-620, 2000.

LIDFORDS, L.M. Behavioural effects of separating the dairy calf immediately or 4 days post-partum. Appl. Anim. Behav. Sci., v.49, p.269-283, 1996.

LOVELL, R.; HILL, A.V. A study of mortality rates of calves in 335 herds in England and Wales (together with some limited observations for Scotland). J. Dairy Res., v.11, p. 225,1940 .

MANCINI, G.; CARBONARA, A.O.; HERMANS, J.F. Immunochemical quantitation of antigens by single radial immunodiffusion. Immunochemistry, v.2, p.253-254, 1965

NOCEK, J.E.; BRAUND, D.G.; WARNER, R.G. Influence of neonatal colostrums administration, immunoglobulin and continued feeding of colostrums on calf gain, health and serum protein. J. Dairy Sci., v.67, p.319-333, 1984.

PAULETTI, P. Efeito de diferentes níveis de imunoglobulinas adquiridas do colostro sobre a flutuação de proteínas séricas e desempenho de bezerras da raça holandesa. 1999. 103p. Dissertação (Mestrado) - Escola Superior de Agricultura Luiz de Queiroz, Universidade de São Paulo, São Paulo.

RAMIN, A.G.; DANIEL, R.C.W.; FENWICK, D.C. et al. Serum immunoglobulin concentrations in young dairy calves and their relationships with weight gain, onset of puberty and pelvic area at 15 months of age. Liv. Prod. Sci., v.45, p.155$163,1996$.

RAUPRICH, A.B.E.; HAMMON, H.M.; BLUM, J. W. Influence of feeding different amounts of first colostrum on metabolic, endocrine, and health status and on growth performance in neonatal calves. J. Anim. Sci., v.78, p.896908, 2000.

STEINHARDT, M.; THIELSCHER, H.H.; LEHR, A. et al Clinical chemical and hematological blood values and adaptations during postnatal life in suckler calves. Deut. Tierarztl Woch., v.102, p.399-405, 1995.

USER'S guide. SAS/ STAT ${ }^{\circledR}$. Cary, NC: SAS Institute, 2000.

WELLS, S.J., DARGATZ , D.A., OTT, S.L. Factors associated with mortality to 22 days of life in dairy herds in the United States. Prev. Vet. Med., v.29, p.9-19, 1996.

WOOD, C.E. Control of parturition in ruminants. J. Reprod. Fertil., v.54, p.115-126, 1999.

ZANETTI, M.A.; LUCCI, C.S.; LOBO, R.B. Duração do período de absorção de imunoglobulinas do colostro por bezerros recém-nascidos. Rev. Soc. Bras. Zootec., v.11, p.612-622, 1982. 